\title{
Engineering Multiphase Metal Halide Perovskites Thin Films for Stable and Efficient Solar Cells
}

\author{
Min Kim, Jetsabel M. Figueroa-Tapia, Mirko Prato, and Annamaria Petrozza*
}

The intrinsic instability of lead halide perovskite semiconductors in an ambient atmosphere is one of the most critical issues that impedes perovskite solar cell commercialization. To overcome it, the use of bulky organic spacers has emerged as a promising solution. The resulting perovskite thin films present complex morphologies, difficult to predict, which can directly affect the device efficiency. Here, by combining in-depth morphological and spectroscopic characterization, it is shown that both the ionic size and the relative concentration of the organic cation, drive the integration of bulky organic cations into the crystal unit cell and the thin film, inducing different perovskite phases and different vertical distribution, then causing a significant change in the final thin film morphology. Based on these studies, a fineengineered perovskite is constructed by employing two different large cations, namely, ethyl ammonium and butyl ammonium. The first one takes part in the 3D perovskite phase formation, the second one works as a surface modifier by forming a passivating layer on top of the thin film. Together they lead to improved photovoltaic performance and device stability when tested in air under continuous illumination. These findings propose a general approach to achieve reliability in perovskite-based optoelectronic devices. solar cells (PSCs) has skyrocketed to a certified PCE of $24.2 \% .{ }^{[5-7]}$ The widely used perovskite materials form a $\mathrm{APbX}_{3}$ structure with $\mathrm{A}=\mathrm{CH}_{3} \mathrm{NH}_{3}{ }^{+}$(methylammonium, MA) and/or $\mathrm{CH}_{3}\left(\mathrm{NH}_{2}\right)_{2}{ }^{+}$(formamidinium, $\mathrm{FA}$ ) and/or cesium ( $\mathrm{Cs}$ ) and $\mathrm{X}=\mathrm{Cl}^{-}, \mathrm{Br}^{-}$, or $\mathrm{I}^{-}$, which crystallizes in a 3D network. ${ }^{[7,8]}$ In spite of high PCEs, the long-term device stability of PSCs remains as one of the crucial issues to be overcome for the large-scale commercialization. ${ }^{\left[{ }^{[9]}\right.}$ To solve the stability issue, the introduction of functional cations within perovskite structures has been proposed.

Recently, 2D halide perovskites have been demonstrated as interesting materials as light absorbers for solar cells and as light emitters for light-emitting diodes (LEDs) because of their wide structural diversity. ${ }^{[10,11]} 2 \mathrm{D}$ perovskites can be conceptually obtained by slicing a generic $\mathrm{ABX}_{3} 3 \mathrm{D}$ perovskite network across the inorganic planes, spaced by large organic cations, typically protonated primary amines with

\section{Introduction}

In the past years, organic-inorganic lead halide perovskites have attracted immense interest due to their excellent optoelectronic properties, such as strong light absorption, long charge carrier diffusion length, and unique defect tolerance. ${ }^{[1-4]}$ More importantly, the power conversion efficiency (PCE) of perovskite

Dr. M. Kim, ${ }^{[+]}$J. M. Figueroa-Tapia, Dr. A. Petrozza

Center for Nano Science and Technology@Polimi

Istituto Italiano di Tecnologia

via Giovanni Pascoli 70/3, 20133 Milan, Italy

E-mail: annamaria.petrozza@iit.it

J. M. Figueroa-Tapia

Dipartamento di Fisica

Politecnico di Milano

Piazza L. Da Vinci, 32, 20133 Milan, Italy

Dr. M. Prato

Materials Characterization Facility

Istituto Italiano di Tecnologia

via Morego 30, 16163 Genova, Italy

The ORCID identification number(s) for the author(s) of this article can be found under https://doi.org/10.1002/aenm.201903221.

${ }^{[+]}$Present address: Division of Chemical Engineering, Jeonbuk National Univeristy, 567 Baekjedaero, Deokjin-gu, Jeonju-si, Jeollabuk-do 54896,

Republic of Korea

DOI: 10.1002/aenm.201903221 an extended linear organic portion. ${ }^{[12]}$ This results in layered structures with the general formula $\mathrm{R}_{2}(\mathrm{~A})_{n-1} \mathrm{~B}_{n} \mathrm{X}_{3 n+1}$, where $\mathrm{R}$ is the additional large cation and $n$ represents the number of inorganic slabs spaced by the large organic cations. Good stability has been demonstrated for devices utilizing 2D perovskites ${ }^{[13,14]}$ as the only active material, however, they generally deliver poor performance because of their inferior carrier mobility and increased non-radiative recombination rates. ${ }^{[11,15,16]}$

In this regard, a multidimensional perovskite, which has $2 \mathrm{D}$ polymorphs together with $3 \mathrm{D}$ perovskites, was brought into perovskite devices, and improved device performances and stability of 2D/3D perovskite have been reported both for solar cells and LEDs. ${ }^{[11,17]}$ By blending 2D-forming bulky cations with a $3 \mathrm{D}$ perovskite-forming solution, $2 \mathrm{D} / 3 \mathrm{D}$ heterostructures can be formed at the grain boundaries or at thin-film interfaces. ${ }^{[17-19]}$ For sure, beginning from all the precursors in the same solution, the perovskite conversion process can become more complex because 3D perovskite and 2D perovskite would go through a discrete perovskite conversion process due to their difference in solubility and crystallization properties, resulting in nonhomogenous morphology. ${ }^{[20]}$ In photovoltaic (PV) devices, bulky organic cation mixed into 3D perovskite can increase the complexity and hamper a reliable morphology control, which has led to broad statistics of PCE for various 2D/3D mixed PSCs in previous literature, ranging from $8 \%$ to $20 \% .^{[16,21-24]}$ Therefore, the effect of the chemical structure of 2D-forming large cation 
on the construction of $2 \mathrm{D} / 3 \mathrm{D}$ perovskite morphology should be investigated thoroughly.

In this work, we investigate how bulky organic cations, which have the same functional group, an ammonium group, and different alkyl lengths, incorporate in multidimensional perovskite phases and affect PSCs in terms of PV properties and device stability. In particular, we compare ethyl ammonium (EA) and butyl ammonium (BA) ions as model molecules. The BA cation has been used to produce 2D/3D perovskite structures, but there has been a broad statistic of PCEs depending on the chemical composition and processing methods of the thin films. ${ }^{[24-28]}$ The EA cation, with a shorter alkyl chain, has been reported as surface passivation molecule and directly within multication 3D perovskites. ${ }^{[29,30]}$ Nevertheless, the conditions which determine how this molecule should be used are yet to be studied more thoroughly. We show how fine-engineering multiphases perovskite devices can achieve both high PCE and improved device stability during the device operation under 1 sun illuminations.

\section{Results and Discussion}

As a control system, we used formamidinium (FA) and cesium (Cs) as A-site cations to form the 3D perovskite phase. The FACs perovskite, with a mole ratio of $\mathrm{FA}: \mathrm{Cs}=0.85: 0.15$, has been reported in solar cells with an average PCE around 17\%. ${ }^{[8]}$ Cations larger than FA and $\mathrm{Cs}$, which are not able to fit within the A site of the $\mathrm{APbX}_{3} 3 \mathrm{D}$ structure, will act as a spacer between $\left[\mathrm{Pb}_{n} \mathrm{X}_{3 n}\right]$ nanoplatelets. In order to select suitable bulky spacers for high-performance solar cells, we started by comparing four different ammoniums: ethyl ammonium (EA), butyl ammonium (BA), phenylethyl ammonium (PEA), and 5-ammonium valeric acid (5AVA) presenting a larger and larger cation size (Figure 1a). The ionic sizes of all the four cations are too large to fit in the tolerance factor below 1, thus, in principle, they form $2 \mathrm{D}$ or $1 \mathrm{D}$ perovskite structure when they occupy the A site (Figure 1b). ${ }^{[29,31-33]}$ We added these large cations into 3D-forming perovskite solution, composed of $\mathrm{FA}$ and $\mathrm{Cs}\left(\mathrm{FA}_{0.85} \mathrm{Cs}_{0.15} \mathrm{PbX}_{3}\right.$ with $\mathrm{X}=\mathrm{I}_{0.9} \mathrm{Br}_{0.1}$ ), and then we grew the polycrystalline thin film by using a conventional solvent-quench method. The perovskite films were sandwiched between $\mathrm{SnO}_{2} / \mathrm{PCBM}$ (phenyl$\mathrm{C}_{61}$-butyric acid methyl ester) and spiro-OMeTAD for standard single-junction device configuration. First, we measured the $J-V$ characteristics of PV devices made with a $10 \%$ mole composition of bulky cation and FACs cations (Figure 1c). The $J-V$ curves show that only the perovskite processed with EA shows enhanced PCE while the other three, BA, PEA, and 5AVA, exhibit lower PV performances. Based on these results, we have focused the rest of our investigation on a systematic comparison between EA and BA, which provides a simplified case study.

We started investigating how changing the mole fraction of EA-mixed and BA-mixed perovskite could affect the PV performance. We incorporated the bulky cation into $\mathrm{FA}_{0.85} \mathrm{Cs}_{0.15}$ $\mathrm{Pb}\left(\mathrm{I}_{0.9} \mathrm{Br}_{0.1}\right)_{3}$ perovskite precursor, ensuring the desired stoichiometry in the resultant films. Figure $2 \mathrm{a}$ shows the average PV parameters obtained from 24 identical devices for each system. In the case of the EA-FACs devices, the PV statistics show an obviously increasing trend for PCE from $x=3 \%$ to $10 \%$. Then, when the EA composition reaches $20 \%$ or above,
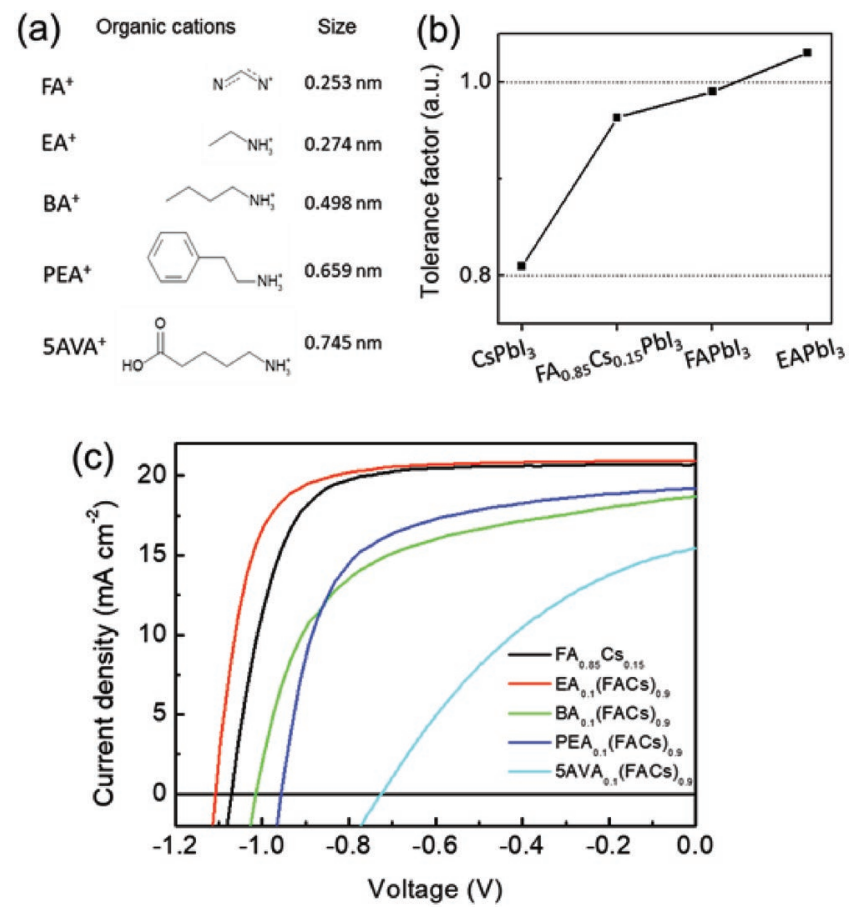

Figure 1. a) A-site organic cations and their ionic sizes: formamidinium (FA), ethyl ammonium (EA), butyl ammonium (BA), phenylethyl ammonium (PEA), and 5-ammonium valeric acid (5AVA). b) Tolerance factor of $\mathrm{APbl}_{3}$ perovskite with various $A$ cations. c) J-V curves of double-cationbased $\left(\mathrm{FA}_{0.85} \mathrm{Cs}_{0.15}\right)$ perovskite $\mathrm{PV}$ devices mixed with bulky organic cations at a mole composition of $10 \%$.

the device shows a decrease in PCE. This trend reflects all the PV parameters such as open circuit voltage $\left(V_{\text {oc }}\right)$, short circuit current density $\left(J_{\mathrm{sc}}\right)$, and fill factors $(\mathrm{FF})$. On the other hand, the BA-FACs devices show a continuous decrease in all of the figures of merit as increasing the BA composition. Thus, we have chosen $10 \%$ concentration of the cation to further advance our investigations.

The control FACs perovskite exhibits a $V_{\text {oc }}$ of $1.08 \mathrm{~V}$, a $J_{\mathrm{sc}}$ of $20.5 \mathrm{~mA} \mathrm{~cm}^{-2}$, and an FF of 0.72 , yielding an average PCE of 16.2\%. ${ }^{[34]}$ The device employing EA10\%-FACs perovskite film achieves higher $V_{\mathrm{oc}}$ of $1.11 \mathrm{~V}$, a $J_{\mathrm{sc}}$ of $21.2 \mathrm{~mA} \mathrm{~cm} \mathrm{~cm}^{-2}$, and an FF of 0.76 , leading to an improved PCE of $17.9 \%$. However, the BA10\%-FACs device exhibits an inferior performance with lower PV parameters: a $V_{\text {oc }}$ of $0.94 \mathrm{~V}$, a $J_{\mathrm{sc}}$ of $17.6 \mathrm{~mA} \mathrm{~cm}$, and an FF of 0.55 . Figure $2 \mathrm{~d}$ shows the corresponding external quantum efficiency (EQE) spectra for the best PV device for each cation. Table 1 summarizes the corresponding PV parameters of the best cells and their averaged values. The EQE of the EA-FACs device has a higher average value in the wavelength range from 300 to $800 \mathrm{~nm}$ compared to the control and BA-FACs. All of the integrated $J_{\mathrm{sc}}$ values from the three devices are well-matched with the values from the $J-V$ results.

The reduced $J_{\mathrm{sc}}$ and $V_{\mathrm{oc}}$ of BA10\%-FACs are closely related to charge recombination processes in the device. First, we measured $J_{\mathrm{sc}}$ under different light intensities $(I)$ ranging from 5 to $100 \mathrm{~mW} \mathrm{~cm}^{-2}$ (Figure 2e). $J_{\mathrm{sc}}$ goes $\propto I^{\alpha}$, where $\alpha$ should be close to 1 if the devices have sufficient electron and hole mobilities and no space charge effects. ${ }^{[35]}$ The fitted $\alpha$ values are 0.994 , 
(a)

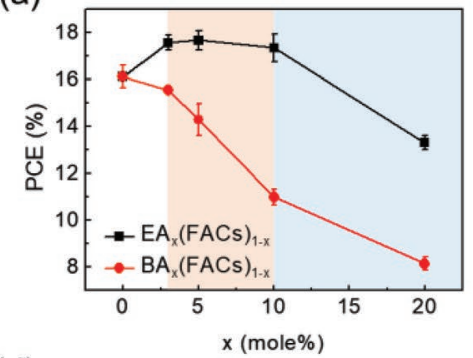

(d)

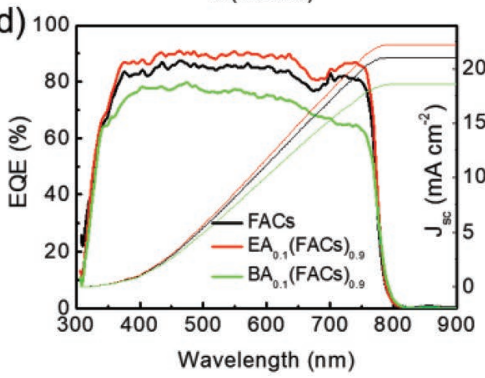

(b)
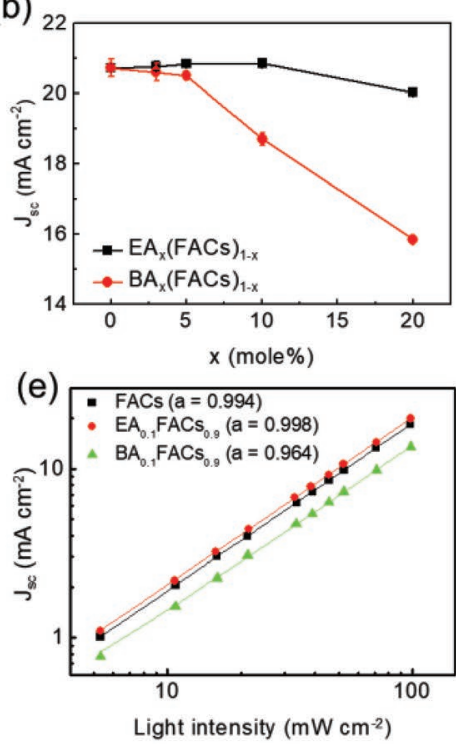

(c)

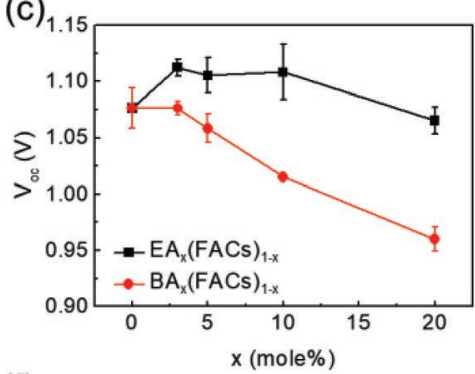

(f)

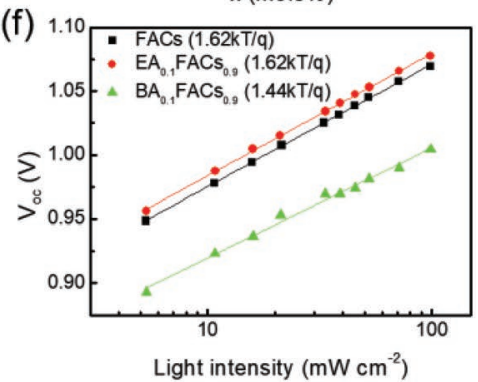

Figure 2. a-c) PV parameters determined from the $J-V$ characteristic of the PSCs prepared with $E A_{x}(F A C s)_{1-x}$ or $B A_{x}(F A C s)_{1-x}$ as a function of mole fraction, $x\left(F A C s=\mathrm{FA}_{0.85} \mathrm{Cs}_{0.15} \mathrm{~Pb}\left(\mathrm{I}_{0.9} \mathrm{Br}_{0.1}\right)_{3}\right)$. d) EQE spectra of the PV devices. e,f) $J_{\mathrm{sc}}$ and $V_{\mathrm{oc}}$ as a function of light intensity.

0.998, and 0.964 for the control FACs, the EA-FACs, and BAFACs based devices, respectively. The BA-FACs device shows a stronger deviation from the unity of slope, which might be related to stronger charge recombination than the control and EA-FACs.

We also measured $V_{\text {oc }}$ at different $I$ (Figure $2 \mathrm{f}$ ). $V_{\text {oc }}$ depends logarithmically on $I$ with a prefactor, the so-called diode ideality factor $n_{\text {id }}$, which can be determined from a measurement of $V_{\text {oc }}$ as a function of $I^{[36]}$

$V_{\mathrm{oc}}=\frac{E_{\mathrm{g}}}{q}-\frac{n_{\mathrm{id}} k T}{q} \ln \left(\frac{I_{0}}{I}\right)$

with $E_{\mathrm{g}}$ the band gap energy, $n_{\mathrm{id}}$ the ideality factor, $k$ the Boltzmann constant, $T$ the temperature, $q$ the elementary charge, and $I_{0}$ a constant with the same unit as $I$. The FACs and EA-FACs devices show $n_{\text {id }}=1.62$, which is reasonably in agreement with the reported values ranging from 1.6 to 1.8 in the previous papers. ${ }^{[36]}$ It is associated with Shockley-Read-Hall recombination processes in the bulk of a mostly intrinsic perovskite film. On the other hand, the BA-FACs device shows $n_{\text {id }}$ of 1.44 together with $V_{\text {oc }}$ values smaller than $1 \mathrm{~V}$. This low $n_{\text {id }}$ along with a small $V_{\text {oc }}$ might indicate strong surface recombination in PV devices, which has been observed for PSCs with an energy-level-unmatched electrode or without hole transporting layer. ${ }^{[36,37]}$ To understand this large difference in PV property between EA-FACs and BA-FACs, the morphology of mixedphase perovskites is further investigated by UV-vis absorption, photoluminescence (PL), and X-ray diffraction (XRD).

UV-vis absorption and PL spectra are measured for the perovskite films with a mixed cation composition of $\mathrm{R}_{x}\left(\mathrm{FA}_{0.85}\right.$ $\left.\mathrm{Cs}_{0.17}\right)_{1-x} \mathrm{~Pb}\left(\mathrm{I}_{0.9} \mathrm{Br}_{0.1}\right)_{3}$, shortly $\mathrm{R}($ mole\%)-FACs $(\mathrm{R}=\mathrm{EA}$ or $\mathrm{BA})$. We prepared the mixed cation perovskite films from starting solutions having the bulky cation R and FACs cation at desirable component ratios and also have $\mathrm{PbX}_{2}$ to be the equivalent molarity to the R-FACs cation for all the solutions. Therefore, the label $\mathrm{EA}_{x}(\mathrm{FACs})_{1-x}$ indicates that the perovskite film was processed from the starting solutions that have $\mathrm{EA}_{x}(\mathrm{FACs})_{1-x} \mathrm{I}$ and $\mathrm{PbX}_{2}$. The EA-FACs perovskites with $5 \%$ and $10 \%$ molar ratio of EA show an almost unchanged absorption profile (Figure 3a). When the EA content reaches 20\%, the mixedphase films show multiple slopes in the absorption spectra. The absorption peaks observed at 494, 522, 560, and $600 \mathrm{~nm}$ can be attributed to the smaller $n$ components $(n=1,2,3$, and 4 ), where $n$ represents the number of inorganic slabs spaced by the large organic cations, suggesting that multiple phase

Table 1. PV parameters obtained from $J-V$ curves under 1 sun illumination.

\begin{tabular}{|c|c|c|c|c|c|c|c|}
\hline & Scan direction & $J_{\mathrm{sc}}\left[\mathrm{mA} \mathrm{cm}^{-2}\right)$ & $V_{o c}[V]$ & $\mathrm{PCE}_{\text {avg }}[\%]$ & $\mathrm{FF}$ & $J_{\text {sc from EQE }}\left[\mathrm{mA} \mathrm{cm}^{-2}\right]$ & $\mathrm{PCE}_{\text {best }}[\%]$ \\
\hline \multirow[t]{2}{*}{ FACs } & Forward & 20.55 & 1.08 & 16.20 & 0.72 & 21.08 & 17.39 \\
\hline & Reverse & 20.52 & 1.08 & 16.26 & 0.72 & & \\
\hline \multirow[t]{2}{*}{$\mathrm{EA}_{0.1}(\mathrm{FACs})_{0.9}$} & Forward & 21.25 & 1.11 & 17.86 & 0.76 & 22.22 & 18.77 \\
\hline & Reverse & 21.21 & 1.11 & 17.95 & 0.76 & & \\
\hline \multirow[t]{2}{*}{$\mathrm{BA}_{0.1}(\mathrm{FACs})_{0.9}$} & Forward & 17.57 & 0.94 & 9.15 & 0.55 & 18.58 & 9.91 \\
\hline & Reverse & 17.52 & 0.97 & 9.12 & 0.53 & & \\
\hline
\end{tabular}


(a)

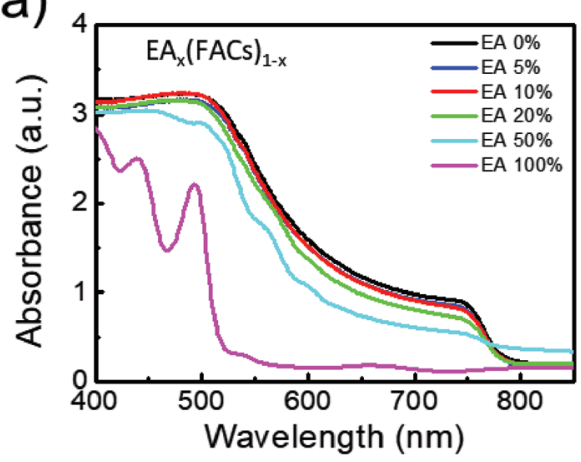

(c)

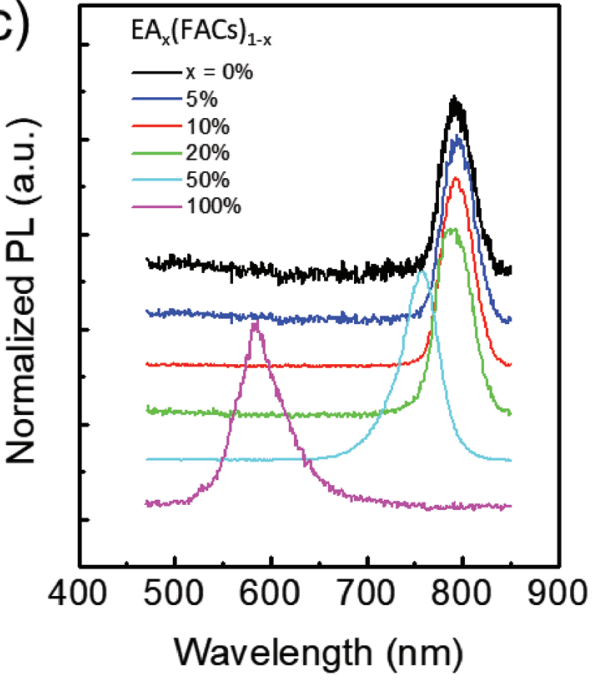

(b)
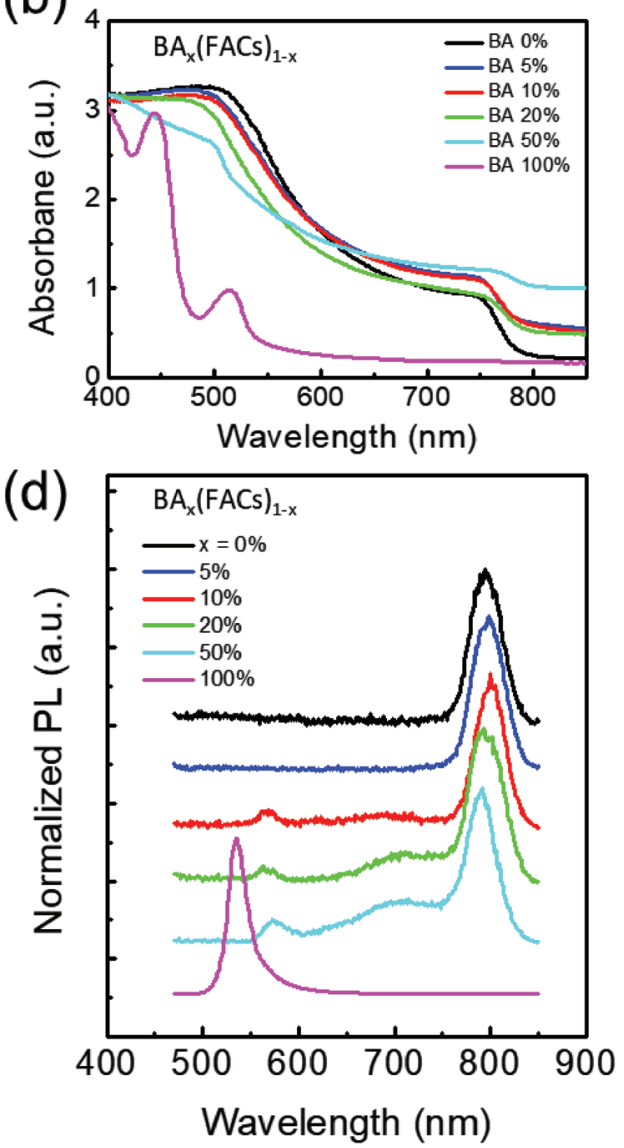

Figure 3. a,b) Absorption spectra and c,d) PL spectra of the 2D/3D perovskite heterostructures with various compositions. At the excitation wavelength of $405 \mathrm{~nm}$, PL was measured from the glass side. We fixed the component ratio of A-site cation and $\mathrm{PbX} \mathrm{X}_{2}$ to be 1:1 for all the solutions. The labels $\mathrm{EA}_{x}(\mathrm{FACs})_{1-x}$ and $\mathrm{BA}_{x}(\mathrm{FACs})_{1-x}$ represent that the perovskite film was processed from the starting solutions that have $\mathrm{EA} \mathrm{FACs}_{\boldsymbol{1}}(\mathrm{FA})_{1-x}$ and $\mathrm{Pb}\left(\mathrm{I}_{0.9} \mathrm{Br}_{0.1}\right)_{2}$ at equimolar ratio.

components coexist in the EA-FACs films. On the other hand, the BA-mixed FACs perovskites show a gradual decrease in absorption as increasing the mole fraction of BA and show strongly enhanced background scattering (Figure 3b). This background scattering suggests a rougher surface profile of BAFACs perovskite films. The absorption edges of the FACs films are maintained also in the BA-FACs till $50 \%$ mole ratio. Thus, the 3D phase disappears only for $100 \%$-EA (processed from ethyl ammonium iodide (EAI): $\mathrm{PbI}_{2}=1: 1$ ) and 100\%-BA (processed from butyl ammonium iodide (BAI): $\mathrm{PbI}_{2}=1: 1$ ) which shows an excitonic absorption peak at $\approx 500 \mathrm{~nm}$.

The pristine FACs shows a main PL emission peak at $795 \mathrm{~nm}$ (Figure 3c). The PL emission peaks slightly shift from 795 to $756 \mathrm{~nm}$ for the samples with the EA amount increasing from $10 \%$ to $50 \%$, which is consistent with the UV-vis absorption results. Importantly, the PL spectra of the films show only one main peak indicating a good transfer of the photoexcitation to the 3D phase with the smaller bandgap. The $100 \%$ EA shows a broad PL emission peak at $585 \mathrm{~nm}$ with a large Stokes shift. The large Stokes shift could in part be attributed to the so-called edge states that are characteristic of layered 2D perovskite materials. ${ }^{[38]}$ On the other hand, the PL spectra of BA-mixed FACs from $10 \%$ to $50 \%$ mole ratio exhibit a main PL emission peak at $795 \mathrm{~nm}$ with well-defined emission signals from low-dimensional perovskites at $580 \mathrm{~nm}$ (corresponding to $n=2$ ) and $700 \mathrm{~nm}$ ( $n=3$ or higher) (Figure 3d). The $100 \%$ BA shows the characteristic PL peak of low-dimension perovskite $n=1\left(\mathrm{BA}_{2} \mathrm{PbI}_{4}\right)$ at $520 \mathrm{~nm}$. These PL peaks at shorter wavelengths are in agreement with values reported in the literature for BA-based low-dimension perovskite arranging into a Ruddlesden-Popper phase. ${ }^{[39]}$ These multiple PL peaks in $2 \mathrm{D} / 3 \mathrm{D}$ perovskite indicate that there is poor transfer of the photoexcitation between low-dimension and high-dimension perovskite.

XRD patterns were measured to understand the arrangement of large cations in the $2 \mathrm{D} / 3 \mathrm{D}$ perovskite structure (Figure 4). The control FACs perovskite shows typical diffraction profiles of 3D perovskite phase which has a (110) diffraction peak at $14.05^{\circ}$. The diffraction profiles of the EA5\%- and EA10\%-FACs perovskite films show similar diffraction peaks to the control FACs perovskite but with a slight shift of the (110) diffraction peak towards smaller angles at $14.0^{\circ}$ without low $n$ phase perovskite formation. Considering the ionic size of the EA cation that is slightly larger than FA, we can assume that EA is compatible with a 3D structure, placing in the "quasi-3D" structure. Thus, we suggest that EA amounts as small as $10 \%$ 
(a)

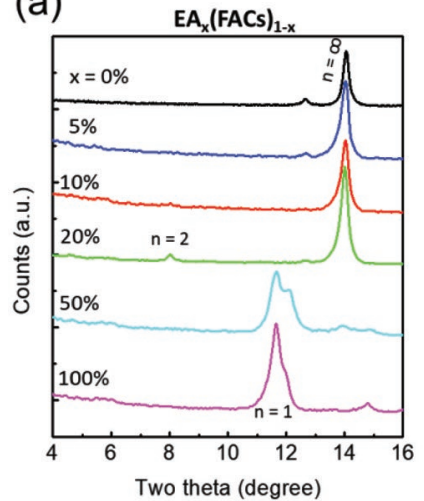

(c)

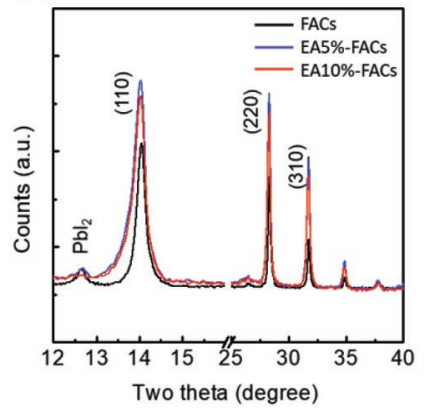

(b)

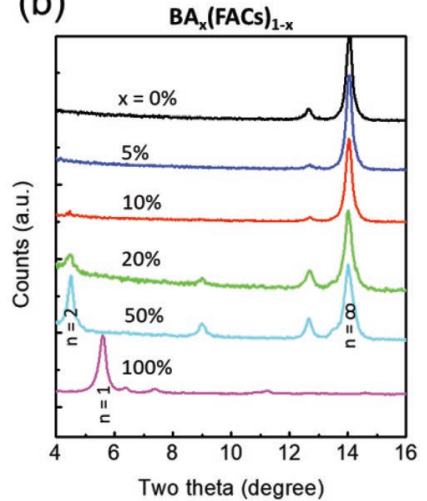

(d)

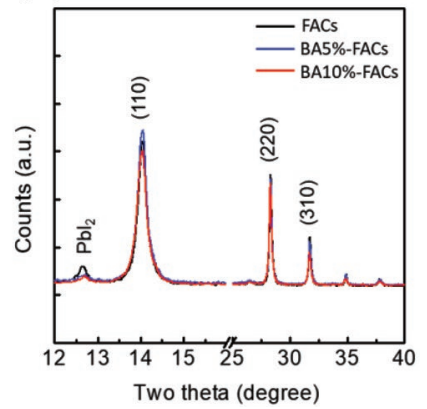

Figure 4. a,b) XRD pattern of the perovskite film with EA and/or BA at various compositions. c,d) Magnification of the XRD peaks on the variation of the EA and/or BA content.

can still form a 3D perovskite phase with a slight lattice expansion. Interestingly, the EA5\%- and EA10\%-FACs films show stronger (110), (220), and (310) diffraction peaks from 3D perovskite phase than the FACs film, which indicates that EA

addition of 5-10\% induces higher crystallinity of the perovskite film (Figure 4c). ${ }^{[40,41]}$ We also observe that the $\mathrm{PbI}_{2}$ peak at $12.7^{\circ}$ reduces with the EA addition, which indicates that the remnant $\mathrm{PbI}_{2}$ gets involved in perovskite formation with EA cation. ${ }^{[42,43]}$ Beyond $x=0.2, \mathrm{EA}_{x}(\mathrm{FACs})_{1-x}$ starts to show a diffraction peak from the low-dimensional phase in the perovskite film at a peak of $8^{\circ}$ (corresponding to $n=2$ ). The diffraction scan of the EA50\%-FACs shows the $n=1$ diffraction peak from $\mathrm{EA}_{2} \mathrm{PbI}_{4}$ phase, located at $11.7^{\circ}$, and a weakened (110) diffraction peak from 3D perovskite phase. ${ }^{[44]}$ The d-spacing from the $n=1$ diffraction peak is $11.1 \AA$, which corresponds to the $(020)$ plane with a stack of EA spacers. On the other hand, the BA-FACs perovskite shows an $n=2$ diffraction peak at $4.5^{\circ}$ already from the BA composition of 10\% (Figure $4 \mathrm{~b}$ ). Due to the large size of BA cation, it does not incorporate into 3D perovskite phase at all, but it forms a 2D perovskite phase. The $n=2$ diffraction peak comes from (020) plane, reflection at $4.5^{\circ}$ is observed for the BA-FACs film, which corresponds to the (020) crystal plane of the 2D perovskite phase. The BA-FACs films display similar or slightly weaker (110), (220), and (310) diffraction peaks from 3D perovskite phase, compared to the FACs control (Figure 4d). As increasing BA composition, diffraction peaks from lowdimensional perovskite phase become prominent until 50\%. In the case of $\mathrm{BA} 100 \%$ perovskite, it exhibits $n=1$ diffraction peak at $5.8^{\circ}$ from $\mathrm{BA}_{2} \mathrm{PbI}_{4}$ phase..$^{[45]}$

To elucidate where the bulky cation locates in the 2D/3D perovskite films, we measured dynamic secondary ion mass spectrometry (DSIMS) and obtained depth profile of ionic species coming from the perovskite film under the $\mathrm{Cs}^{+}$ionic sputtering. The control FACs perovskite film shows a homogenous distribution of every component including $\mathrm{Pb}, \mathrm{CN}_{2}$ ion, and I ion along with the depth profile (Figure 5a). The EA10\%FACs perovskite also exhibits a similar depth profile except a small bump locating an accumulation of $\mathrm{CN}_{2}$ at the buried
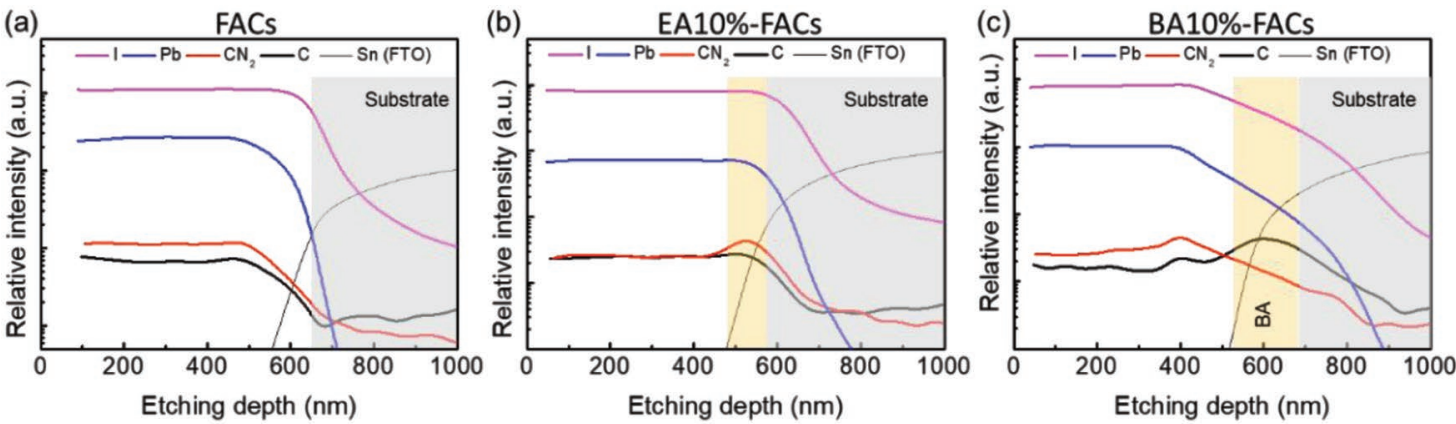

(d)
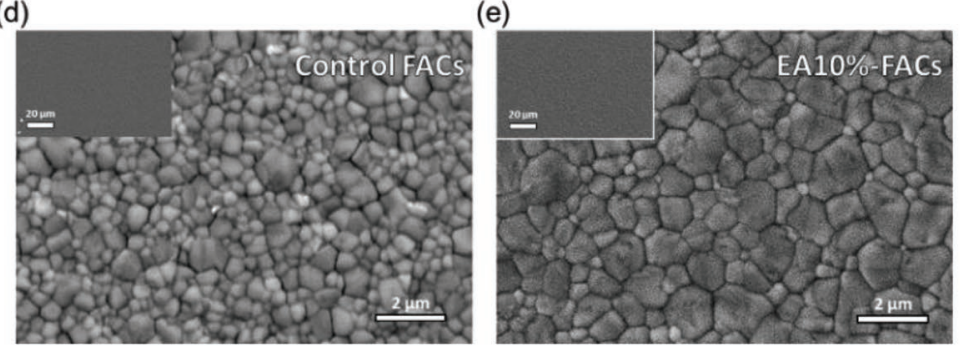

(f)

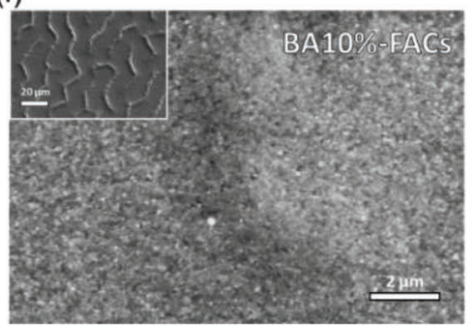

Figure 5. a-c) Dynamic-SIMS depth profiles of secondary ions: $\mathrm{C}, \mathrm{CN}_{2}, \mathrm{~Pb}, \mathrm{I}$, and $\mathrm{Sn}$ ions were detected as a function of etching depth. d,e) Comparison of the emission spectra of the 2D/3D perovskite film illuminated from the front and glass (back) sides of the film. 
interface (Figure 5b). Discerning FA $\left(\mathrm{CH}_{5} \mathrm{~N}_{2}, \mathrm{MW}=172\right)$ and EA $\left(\mathrm{C}_{2} \mathrm{H}_{8} \mathrm{~N}, \mathrm{MW}=173\right)$ cations is difficult since they have similar molecular weights. However, it has been reported by previous works that bulky cations in 2D/3D perovskites are likely to accumulate at the buried interface. ${ }^{[4-48]}$ X-ray photoelectron spectroscopy measurement shows an identical surface chemical composition of EA-FACs and FACs film (Table S1, Supporting Information), which may indicate that EA falls to the buried interface. In the case of the BA10\%-FACs film, the depth profile displays a strong peak of carbon signal at the buried interface with a thickness around $150 \mathrm{~nm}$, which can be definitely differentiated from the $\mathrm{CN}_{2}$ curve that already shows a substantial decrease at the buried interface (Figure $5 \mathrm{c}$ ). This carbon accumulation comes from the BA cation that has three more carbons than FA. Such vertical distribution is also confirmed by the detection of PL spectra from the top and buried perovskite surface (Figure S2, Supporting Information).

We measured scanning electron microscope (SEM) images of the control FACs, EA10\%-FACs, and BA10\%-FACs perovskites to investigate the perovskite film morphologies. The control FACs show a quite broad distribution of crystal size ranging from 0.2 to $1 \mu \mathrm{m}$, whereas the EA-FACs exhibits larger crystals averagely over $1 \mu \mathrm{m}$ and smoother surface morphology with reduced surface roughness. The EA-FACs film seems to contain more compactly packed crystals. On the other hand, the BA-FACs show a much rougher surface morphology than the control and EA-FACs. In particular, the topology of the BA-FACs film shows a wrinkly textured morphology with a width of $20 \mu \mathrm{m}$ between wrinkles. This can be explained by a high degree of volume changes that occur during perovskite conversion processes due to the much larger size of BA cation compared to FA and $\mathrm{Cs}$, resulting in the development of in-plane compressive stress that leads to the observed wrinkling upon releasing energy. ${ }^{[49]}$ Especially, the BA-based low $n$ perovskite phase dominantly forms at the buried interface, strongly affecting the overall film morphology development. Interestingly, this wrinkly morphology also appears in the case of EA50\%-FACs, with a similar valley width of $20 \mu \mathrm{m}$, which supports that low $n$ perovskite formation during rapid crystallization can affect resultant film formation strongly (Figure S3, Supporting Information).

In Figure 6, we present a schematic drawing which summarizes the thin-film morphology evolution upon doping with large organic cations. Up to $10 \%$ load with the EA cation, the molecule remains disperse within the $3 \mathrm{D}$ phase and at the bottom without forming a 2D perovskite phase. Only above $10 \%$ of the EA cation concentration, 2D crystalline phases start forming. Most importantly, the incorporation of EA induces a smooth, compact, and large-size perovskite crystal formation as confirmed by XRD and SEM measurements. This also results in a lower defect density and enhanced PL emission with respect to the control sample (Figure S4, Supporting Information) and a good thermal stability (Figure S7, Supporting Information). Above 20\% EA mole fraction, perovskite starts to form $n=2$ phase layer at the buried interface, and the thin film morphology also shows smaller grains. By introducing a novel molecular descriptor for larger molecular cations, the "globularity factor" (i.e., the discrepancy of the molecular shape and an ideal sphere), it was shown that EA may be a suitable

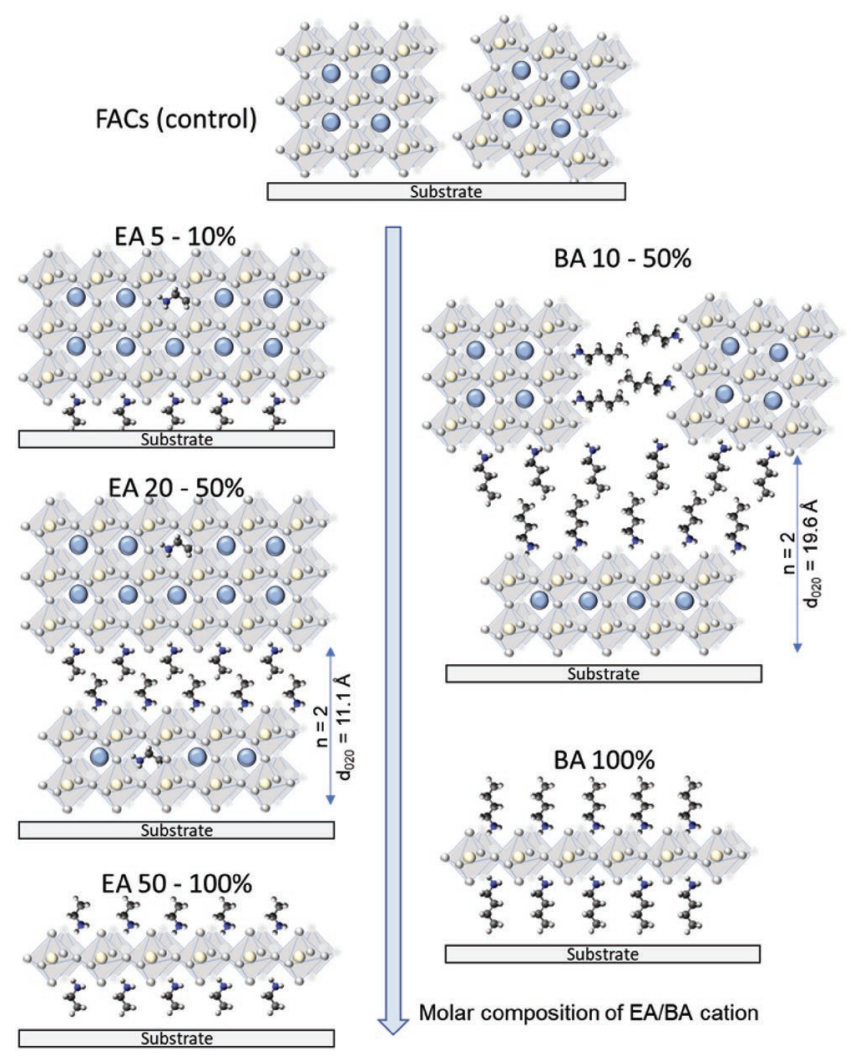

Figure 6. Schematic representations of the 2D/3D perovskite starting from various compositions and bulk cations.

candidate for multi-cation 3D perovskites. ${ }^{[29,50]} \mathrm{MA} / \mathrm{EA}$ PSCs with very large EA loading were characterized. ${ }^{[29]}$ However, here it is clear that different cations combinations, i.e., the addition of FA/Cs, can affect the stabilization of single components within the structure and the thin-film morphology at different loads. On the other hand, even with a small amount of BA addition, the perovskite thin film shows $n=2$ phase formation and a much rough surface morphology with small perovskite grains. The inclusion of BA in the $3 \mathrm{D}$ perovskite phase induces strong vertical segregation and large volume expansion, which substantially affects 2D/3D film formation. Though the film still shows good emissive and thermal properties (Figures S4 and S7, Supporting Information), this segregation will act as a barrier for charge transport and collection to the electrode and induces surface recombination, as shown in Figure 2.

To gain insight into the operational stability of the mixed 2D/3D PSCs, PV devices, not encapsulated, were tracked at its maximum power point (MPP) under 1 sun illumination (UV spectrum included) for $60 \mathrm{~h}$ in a way of simulating day and night cycle for $12 \mathrm{~h}$ illumination and overnight storages (Figure 7a). We compared the control FACs, EA10\%-FACs, and BA10\%-FACs devices. This cycling test monitors not only the device operational stability but also the recovering property in the dark. ${ }^{[51]}$ The devices were measured in ambient condition at a relative humidity $(\mathrm{RH})$ of $40-70 \%$ and a room temperature of $19-21{ }^{\circ} \mathrm{C}$. The MPP of the EA10\%-FACs device is stable at $17 \%$ without showing any decay over the entire probing period of $60 \mathrm{~h}$. The control FACs and BA10\%-FACs devices show a 


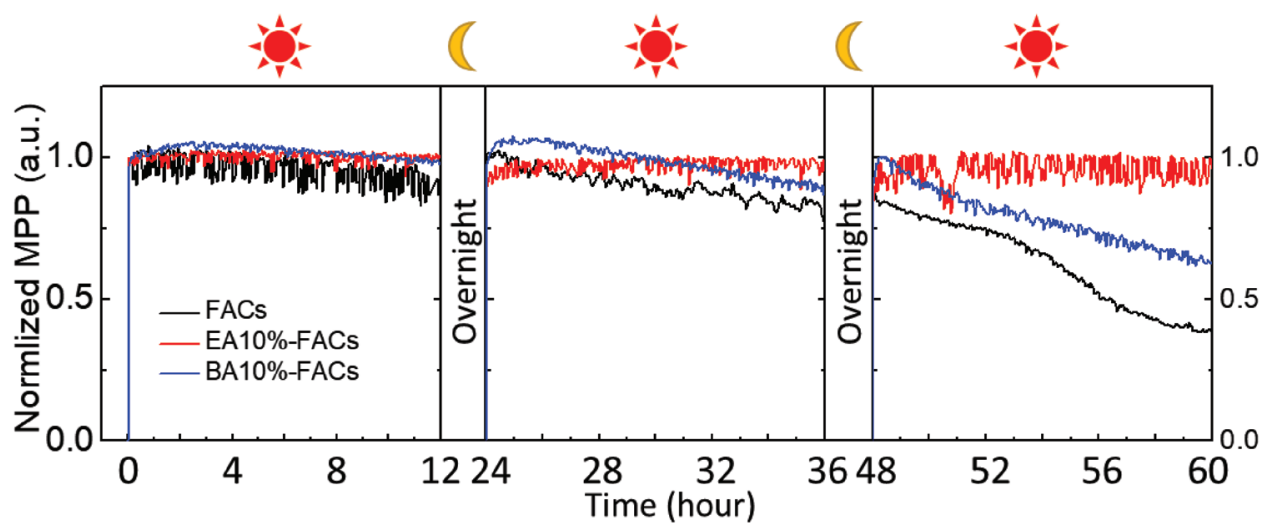

Figure 7. Operational stability tests without encapsulation by tracking at their MPPs under 1 sun illumination by xenon lamp. RH $40-70 \%$.

stark contrast to the EA10\%-FACs. For the first day stability test, they do not show any decrease in maximum power point tracking (MPPT) similar to the EA-FACs device, but on the second day, it exhibits an apparent decay in MPPT by $20 \%$. In addition, on the third day, even though the MPP recovers back of its initial value, it rapidly decays to $40 \%$ of the PCE over the $12 \mathrm{~h}$ illumination. The BA-FACs device also exhibits a similar trend to the control FACs device. Especially, on the third day of illumination, it obviously shows a decay in PCE during the testing process by $40 \%$. This trend is in agreement with the reported results, which showed a decrease by $40-60 \%$ in MPPT during tens of hours without encapsulation in ambient atmosphere. ${ }^{[17,19]}$

(a)

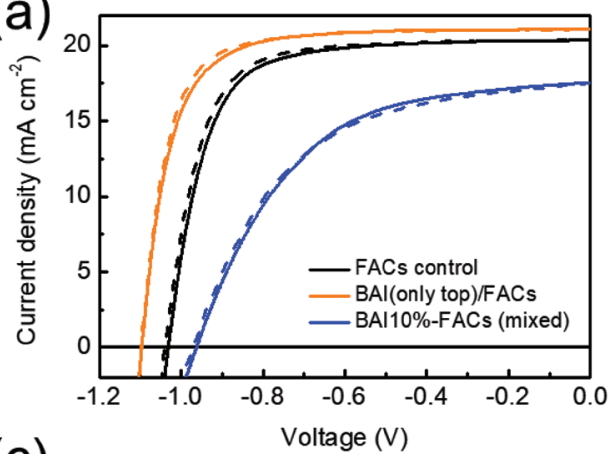

(c)

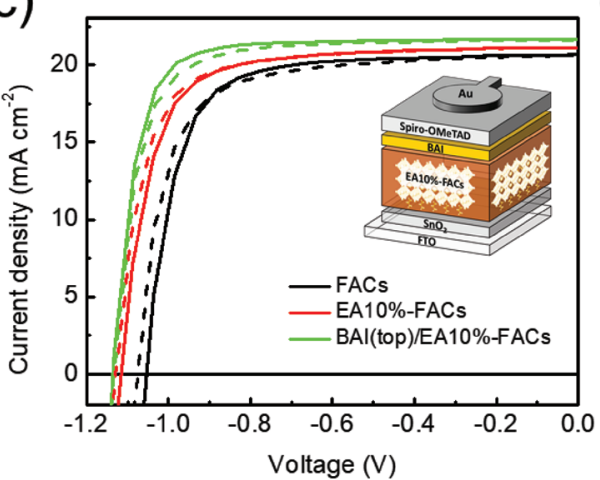

Armed with the knowledge developed in this study, we further engineered our PV devices. Because the addition of the bulky cation, BA, in the precursor solution induces a dramatic morphological change, instead we deposited BAI thin film on top of perovskite not to disrupt the morphology, while acting as a surface encapsulation agent on the control FACs perovskite (Figure 8a). For comparison, we also test thin films with EAI-treated surfaces (Figure 8b). The BAI-coated FACs device shows a slightly higher $V_{\text {oc }}(1.12 \mathrm{~V})$ compared to the reference without the BAI layer $(1.08 \mathrm{~V})$ and the one with BAI mixed within the precursors' solutions (Figure 8a and Table S2, Supporting Information). Note that by depositing the BAI salt on the FACs and EA-FACs surfaces, even though the samples

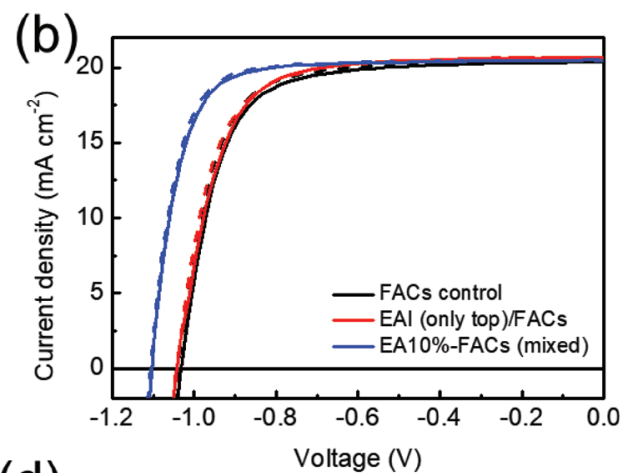

(d)

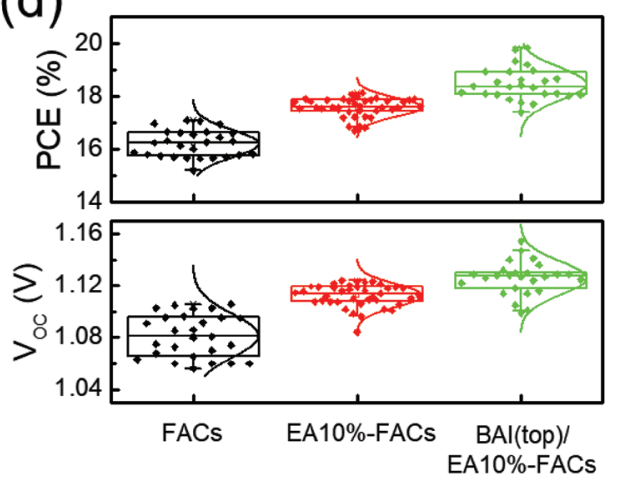

Figure 8. $J-V$ curves of a) the FACs device with BAI layer on top of perovskite (orange) and the BA10\%-FACs device (blue) and those of b) the FACs device with EAI layer on top of perovskite (red) and the EA10\%-FACs device (blue). The dashed lines are for forward scans and the solid lines are for reverse scans. c) J-V curves of the EA10\%-FACs device with BAI layer on top of perovskite (green), the EA10\%-FACs device (blue), and the FACs control device (black). d) Statistical PCE and $V_{\text {oc }}$ for the PSCs obtained from 24 devices. 
were not subjected to thermal annealing, we found that a $2 \mathrm{D}$ phase is formed probably (see Figures S9 and S10, Supporting Information) due to a diffusion of the large cation within the first tens of seconds. ${ }^{[52-54]}$ In the case of EAI-overcoating, the EAI(top)/FACs perovskite shows a similar $J-V$ curve to the control device without an improvement in $V_{\text {oc }}(1.08 \mathrm{~V})$, contrary to the increase in $V_{\text {oc }}(1.12 \mathrm{~V})$ of the EA-mixed perovskite (Figure $8 \mathrm{~b}$ ). As an obvious conclusion, we tried to combine this BAI interlayer modification with the high-performing EA-FACs PV device. We fabricated a multistructured 2D/3D perovskite PV device that has EA10\%-FACs in the bulk and BAI thin film between the perovskite and spiro-OMeTAD. The BAI/EA10\%FACs device achieves the highest PCE with the average $V_{\text {oc }}$ of $1.14 \mathrm{~V}$ and the stabilized PCE of $18 \%$ with the champion PCE of $18.8 \%$ (Figure $8 \mathrm{c}, \mathrm{d}$ ). We believe that our approach to utilize BAI-passivated and EA-doped perovskite will provide important insights for the research community to design perovskite materials to achieve stabilized PCEs over long-term operation.

\section{Conclusion}

We investigated how the integration of bulky cations can affect the structural, optical, and morphological properties of FAC$\mathrm{SPbX}_{3}$ perovskite thin films. We have chosen two molecules that represent an ideal model system since they have the same functional groups but different sizes, i.e., ethyl ammonium and butyl ammonium. By following the morphological evolution and the relative consequences on the optoelectronic mechanisms of the solar cells, we have engineered a multiphase system where the ethyl ammonium is dispersed within the thin film and mainly improves the crystallinity of the perovskite by entering the crystal unit, while the bigger butyl ammonium is used to treat the 3D surface, passivating it. This structure can achieve both improved PCE and improved device operational stability. This study provides a promise for improving the air stability of perovskite-based optoelectronic devices.

\section{Experimental Section}

Materials: All materials were purchased and used as received. $\mathrm{PbI}_{2}$, $\mathrm{PbBr}_{2}$, and $\mathrm{Csl}$ were purchased from Alfa Aesar. Formamidinium iodide (FAI), EAI, and BAI were obtained from Dyesol. $N, N$-dimethylformamide (DMF) and dimethylsulfoxide (DMSO) were purchased from Sigma Aldrich. Spiro-OMeTAD was purchased from Luminescence Technology.

Perovskite Fabrication: Fluorine-doped tin oxide (FTO)-coated glass was etched with zinc powder and $2 \mathrm{M}$ aqueous $\mathrm{HCl}$ solution for electrode pattern. The indium tin oxide substrates were washed with $2 \%$ Hellmanex in water, deionized water, iso-propanol, acetone, and iso-propanol sequentially in a sonication bath for $\approx 15 \mathrm{~min}$, followed by $\mathrm{O}_{2}$ plasma cleaning for $10 \mathrm{~min}$. A patterned and cleaned FTO substrate was covered with $\mathrm{a} \approx 10 \mathrm{~nm}$ thick $\mathrm{SnO}_{2}$ layer by spin coating of a diluted $\mathrm{SnO}_{2}$ nanoparticle solution (Alfa Aesar) and annealed at $180^{\circ} \mathrm{C}$ for $1 \mathrm{~h}$ And then, PCBM solution ( $10 \mathrm{mg} \mathrm{mL}^{-1}$ in chlorobenzene) was deposited on $\mathrm{SnO}_{2}$, followed by annealing at $100^{\circ} \mathrm{C}$ for $10 \mathrm{~min}$. The 3D perovskite, $\mathrm{FA} / \mathrm{Cs}$ perovskite, was prepared by dissolving different molar quantities of $\mathrm{FAI}, \mathrm{Csl}, \mathrm{Pbl}_{2}$, and $\mathrm{PbBr}_{2}$, which formed $\mathrm{FA}_{0.85} \mathrm{Cs}_{0.15} \mathrm{~Pb}\left(\mathrm{I}_{0.9} \mathrm{Br}_{0.1}\right)_{3}$, in DMF and DMSO at a volume ratio of $7: 3$. For $2 \mathrm{D} / 3 \mathrm{D}$ perovskite solutions, stoichiometric precursor solutions were prepared by mixing FACs with EAl and/or BAl to get the molar ratio between $\mathrm{FA}_{0.85} \mathrm{Cs}_{0.15}$ and large cation (EA or BA), gradually changing from 1:0 to 0:1, while keeping the $\mathrm{Pb}\left(\mathrm{I}_{0.9} \mathrm{Br}_{0.1}\right)_{2}$ molarity all the same. After stirring for $6 \mathrm{~h}$ at room temperature, the perovskite solutions were spin-coated with two steps (the first step at $1000 \mathrm{rpm}$ for $10 \mathrm{~s}$ and the second step at $4000 \mathrm{rpm}$ for $30 \mathrm{~s}$ ). During the second step, $200 \mu \mathrm{L}$ of anhydrous chlorobenzene was quickly dripped at the 15th s. The thin films were then transferred to a hotplate and annealed at $170{ }^{\circ} \mathrm{C}$ for $10 \mathrm{~min}$. The whole synthesis process was conducted in the nitrogen-filled glovebox. For PV device fabrication, a Spiro-OMeTAD solution was spin-coated on the perovskite layer at $4000 \mathrm{rpm}$ for $30 \mathrm{~s}$. Spiro-OMeTAD solution was prepared by dissolving $73 \mathrm{mg}$ of Spiro-OMeTAD in $1 \mathrm{~mL}$ chlorobenzene $(99.8 \%$; Sigma-Aldrich), to which was added $28.8 \mathrm{~mL}$ of 4-tert-butylpyridine (96\%, Sigma-Aldrich) and $17.5 \mathrm{~mL}$ lithium bis(trifluoromethanesulfonyl) imide (LiTFSI) solution (520 mg LiTSFI in $1 \mathrm{~mL}$ acetonitrile, $99.8 \%$, Sigma-Aldrich). Finally, $75 \mathrm{~nm}$ gold was thermally evaporated on top of the device at a pressure of $1 \times 10^{-6} \mathrm{mbar}$ to form the back contact.

Characterization: UV-vis absorption spectra were recorded with a UV-vis Varian Cary 5000. Perovskite films were prepared on bare glass substrates. XRD patterns were recorded with a Bruker D8 Advance diffractometer with Bragg-Brentano geometry equipped with a $\mathrm{Cu} \mathrm{K} \alpha_{1}$ $(\lambda=1.544060 \AA)$ anode, operating at $40 \mathrm{kV}$ and $40 \mathrm{~mA}$. All the diffraction patterns were collected at room temperature, with a step size of 0.021 in symmetric scan reflection mode and an acquisition time of $1 \mathrm{~s}$. DSIMS measurements taken were performed by using an SIMS system (IMS 6F, CAMECA, France) at the National Center for National Institute for Nanomaterials Technology (Pohang, Korea). The impact energy was $10 \mathrm{keV}$ and $\mathrm{Cs}^{+}$ions were used as the primary ions; the analysis area was $30 \mathrm{~mm}$, and the raster size was $250 \mu \mathrm{m} \times 250 \mu \mathrm{m}$, accepting negatively charged secondary ions from the central $20 \%$ of the crater area. ${ }^{12} \mathrm{C},{ }^{12} \mathrm{C}^{14} \mathrm{~N}_{2},{ }^{79} \mathrm{Br},{ }^{107} \mathrm{Ag},{ }^{120} \mathrm{Sn},{ }^{127} \mathrm{I},{ }^{208} \mathrm{~Pb}$ ions were detected. The samples were sufficiently thin and conductive so that no charge compensation was required. SEM images were obtained using a JCM-6010LV, JEOL at 15-20 kV electron beam. For steady-state $\mathrm{PL}$, excitation light was provided by a CW diode laser (Oxxius laserboxx, wavelength $405 \mathrm{~nm}$ ). The perovskite films were mounted inside a vacuum chamber (pressure of $10^{-5} \mathrm{mbar}$ ), and PL was collected in reflection mode and focused into a fiber coupled to a spectrometer (Ocean Optics Maya Pro 2000).

PV Characterization: The current density-voltage $(U-V)$ characteristics were measured with a computer-controlled Keithley 2420 source meter in the air without any device encapsulation. The simulated Air Mass 1.5 Global (AM 1.5G) irradiance was provided with a class AAA Newport solar simulator. The light intensity was calibrated with a silicon reference cell with a spectral mismatch factor of 0.99 . The active area of the complete device was determined by an illumination-shadowing mask which is $0.0935 \mathrm{~cm}^{-2}$. For the $J-V$ measurement, the scan rate was $0.05 \mathrm{~V} \mathrm{~s}^{-1}$ for the slow scan. The forward scan started from $0 \mathrm{~V}$ (the short circuit condition) to $1.4 \mathrm{~V}$, while the reverse scan was from 1.4 to $0 \mathrm{~V}$. Preconditional stress was not done for PV measurements. The EQE was measured with a home-built setup. EQE spectra were recorded using the monochromated (Bentham) output from a tungsten halogen lamp calibrated with a Newport UV-818 photodiode. The stability test was performed in an ambient atmosphere (temperature: $\approx 24{ }^{\circ} \mathrm{C}$, $\mathrm{RH}=40-70 \%$ ) by using Arkeo stability platform (Cicci Research, Italy). Devices were maintained at the MPP using a MPP tracking algorithm under 1 sun illumination, and $I-V$ curves were characterized every $1 \mathrm{~h}$ by an electronic system.

\section{Supporting Information}

Supporting Information is available from the Wiley Online Library or from the author.

\section{Acknowledgements}

M.K. acknowledges funding from EU Horizon 2020 via a Marie Sklodowska Curie Fellowship (Project no. 797546, FASTEST). The 
authors thank the National Institute for Nanomaterials Technology (NINT, Korea) for DSIMS measurements and also thank Dr. E. M. Speller for help with PL measurements. M.K's present address was updated on February 25, 2020

\section{Conflict of Interest}

The authors declare no conflict of interest.

\section{Keywords}

bulky cations, metal halide perovskites, mixed dimension, solar cells, stability

Received: October 1, 2019

Revised: December 13, 2019 Published online: January 30, 2020

[1] S. D. Stranks, G. E. Eperon, G. Grancini, C. Menelaou, M. J. P. Alcocer, T. Leijtens, L. M. Herz, A. Petrozza, H. J. Snaith, Science 2013, 342, 341

[2] B. Saparov, D. B. Mitzi, Chem. Rev. 2016, 116, 4558.

[3] G. Xing, N. Mathews, S. Sun, S. S. Lim, Y. M. Lam, M. Grätzel, S. Mhaisalkar, T. C. Sum, Science 2013, 342, 344.

[4] D. Meggiolaro, S. G. Motti, E. Mosconi, A. J. Barker, J. Ball, C. Andrea Riccardo Perini, F. Deschler, A. Petrozza, F. De Angelis, Energy Environ. Sci. 2018, 11, 702.

[5] A. Kojima, K. Teshima, Y. Shirai, T. Miyasaka, J. Am. Chem. Soc. 2009, 131, 6050

[6] M. M. Lee, J. Teuscher, T. Miyasaka, T. N. Murakami, H. J. Snaith, Science 2012, 338, 643.

[7] W. S. Yang, B.-W. Park, E. H. Jung, N. J. Jeon, Y. C. Kim, D. U. Lee, S. S. Shin, J. Seo, E. K. Kim, J. H. Noh, S. I. Seok, Science 2017, 356, 1376.

[8] S.-H. Turren-Cruz, A. Hagfeldt, M. Saliba, Science 2018, 362, 449.

[9] L. Meng, J. You, Y. Yang, Nat. Commun. 2018, 9, 5265.

[10] G. Grancini, M. K. Nazeeruddin, Nat. Rev. Mater. 2019, $4,4$.

[11] D. Cortecchia, W. Mróz, S. Neutzner, T. Borzda, G. Folpini, R. Brescia, A. Petrozza, Chem 2019, 5, 2146.

[12] L. Mao, C. C. Stoumpos, M. G. Kanatzidis, J. Am. Chem. Soc. 2019, $141,1171$.

[13] H. Tsai, W. Nie, J.-C. Blancon, C. C. Stoumpos, R. Asadpour, B. Harutyunyan, A. J. Neukirch, R. Verduzco, J. J. Crochet, S. Tretiak, L. Pedesseau, J. Even, M. A. Alam, G. Gupta, J. Lou, P. M. Ajayan, M. J. Bedzyk, M. G. Kanatzidis, A. D. Mohite, Nature 2016, 536, 312.

[14] D. Thrithamarassery Gangadharan, D. Ma, Energy Environ. Sci. 2019, 12, 2860.

[15] J. Yan, W. Qiu, G. Wu, P. Heremans, H. Chen, J. Mater. Chem. A 2018, 6, 11063

[16] S. Zhang, S. M. Hosseini, R. Gunder, A. Petsiuk, P. Caprioglio, C. M. Wolff, S. Shoaee, P. Meredith, S. Schorr, T. Unold, P. L. Burn, D. Neher, M. Stolterfoht, Adv. Mater. 2019, 31, 1901090.

[17] J.-W. Lee, Z. Dai, T.-H. Han, C. Choi, S.-Y. Chang, S.-J. Lee, N. De Marco, H. Zhao, P. Sun, Y. Huang, Y. Yang, Nat. Commun. 2018, 9, 3021.

[18] T. Niu, J. Lu, M.-C. Tang, D. Barrit, D.-M. Smilgies, Z. Yang, J. Li, Y. Fan, T. Luo, I. McCulloch, A. Amassian, S. Liu, K. Zhao, Energy Environ. Sci. 2018, 11, 3358.

[19] W. Ke, L. Mao, C. C. Stoumpos, J. Hoffman, I. Spanopoulos, A. D. Mohite, M. G. Kanatzidis, Adv. Energy Mater. 2019, 9, 1803384.
[20] Y. Lin, Y. Fang, J. Zhao, Y. Shao, S. J. Stuard, M. M. Nahid, H. Ade, Q. Wang, J. E. Shield, N. Zhou, A. M. Moran, J. Huang, Nat. Commun. 2019, 10, 1008.

[21] T. Zhang, M. I. Dar, G. Li, F. Xu, N. Guo, M. Grätzel, Y. Zhao, Sci. Adv. 2017, 3, el700841.

[22] T. M. Koh, V. Shanmugam, J. Schlipf, L. Oesinghaus, P. Müller-Buschbaum, N. Ramakrishnan, V. Swamy, N. Mathews, P. P. Boix, S. G. Mhaisalkar, Adv. Mater. 2016, 28, 3653.

[23] N. Li, Z. Zhu, C.-C. Chueh, H. Liu, B. Peng, A. Petrone, X. Li, L. Wang, A. K.-Y. Jen, Adv. Energy Mater. 2017, 7, 1601307.

[24] Z. Wang, Q. Lin, F. P. Chmiel, N. Sakai, L. M. Herz, H. J. Snaith, Nat. Energy 2017, 2, 17135.

[25] D. H. Cao, C. C. Stoumpos, O. K. Farha, J. T. Hupp, M. G. Kanatzidis, J. Am. Chem. Soc. 2015, 137, 7843.

[26] X. Zhang, X. Ren, B. Liu, R. Munir, X. Zhu, D. Yang, J. Li, Y. Liu, D.-M. Smilgies, R. Li, Z. Yang, T. Niu, X. Wang, A. Amassian, K. Zhao, S. Liu, Energy Environ. Sci. 2017, 10, 2095.

[27] X. Zhang, G. Wu, S. Yang, W. Fu, Z. Zhang, C. Chen, W. Liu, J. Yan, W. Yang, H. Chen, Small 2017, 13, 1700611

[28] N. Zhou, Y. Shen, L. Li, S. Tan, N. Liu, G. Zheng, Q. Chen, H. Zhou, J. Am. Chem. Soc. 2018, 140, 459.

[29] S. Gholipour, A. M. Ali, J.-P. Correa-Baena, S.-H. Turren-Cruz, F. Tajabadi, W. Tress, N. Taghavinia, M. Grätzel, A. Abate, F. De Angelis, C. A. Gaggioli, E. Mosconi, A. Hagfeldt, M. Saliba, Adv. Mater. 2017, 29, 1702005.

[30] E. A. Alharbi, A. Y. Alyamani, D. J. Kubicki, A. R. Uhl, B. J. Walder, A. Q. Alanazi, J. Luo, A. Burgos-Caminal, A. Albadri, H. Albrithen, M. H. Alotaibi, J.-E. Moser, S. M. Zakeeruddin F. Giordano, L. Emsley, M. Grätzel, Nat. Commun. 2019, 10, 3008.

[31] D. Liu, Q. Li, K. Wu, RSC Adv. 2019, 9, 7356.

[32] M.-H. Li, H.-H. Yeh, Y.-H. Chiang, U.-S. Jeng, C.-J. Su, H.-W. Shiu, Y.-J. Hsu, N. Kosugi, T. Ohigashi, Y.-A. Chen, P.-S. Shen, P. Chen, T.-F. Guo, Adv. Mater. 2018, 30, 1801401.

[33] T. Nakajima, H. Yamauchi, T. Goto, M. Yoshizawa, T. Suzuki, T. Fujimura, J. Magn. Magn. Mater. 1983, 31-34, 1189.

[34] N. D. Pham, C. Zhang, V. T. Tiong, S. Zhang, G. Will, A. Bou, J. Bisquert, P. E. Shaw, A. Du, G. J. Wilson, H. Wang, Adv. Funct. Mater. 2019, 29, 1806479.

[35] V. D. Mihailetchi, H. X. Xie, B. de Boer, L. J. A. Koster, P. W. M. Blom, Adv. Funct. Mater. 2006, 16, 699

[36] W. Tress, M. Yavari, K. Domanski, P. Yadav, B. Niesen, J. P. Correa Baena, A. Hagfeldt, M. Graetzel, Energy Environ. Sci. 2018, 11, 151 .

[37] K. Miyano, M. Yanagida, N. Tripathi, Y. Shirai, Appl. Phys. Lett. 2015, 106, 093903.

[38] J.-C. Blancon, H. Tsai, W. Nie, C. C. Stoumpos, L. Pedesseau, C. Katan, M. Kepenekian, C. M. M. Soe, K. Appavoo, M. Y. Sfeir, S. Tretiak, P. M. Ajayan, M. G. Kanatzidis, J. Even, J. J. Crochet, A. D. Mohite, Science 2017, 355, 1288.

[39] C. C. Stoumpos, D. H. Cao, D. J. Clark, J. Young, J. M. Rondinelli, J. I. Jang, J. T. Hupp, M. G. Kanatzidis, Chem. Mater. 2016, 28, 2852.

[40] C. Bi, Y. Shao, Y. Yuan, Z. Xiao, C. Wang, Y. Gao, J. Huang, J. Mater. Chem. A 2014, 2, 18508.

[41] J. Lei, H. Wang, F. Gao, S. Liu, Phys. Status Solidi A 2018, 215, 1700959.

[42] P. Chen, Y. Bai, S. Wang, M. Lyu, J.-H. Yun, L. Wang, Adv. Funct. Mater. 2018, 28, 1706923.

[43] Y. Cho, A. M. Soufiani, J. S. Yun, J. Kim, D. S. Lee, J. Seidel, X. Deng, M. A. Green, S. Huang, A. W. Y. Ho-Baillie, Adv. Energy Mater. 2018, 8, 1703392.

[44] J. Zhou, Z. Ye, J. Hou, J. Wu, Y.-Z. Zheng, X. Tao, J. Mater. Chem. A $2018,6,22626$ 
[45] J. Wang, X. Yao, W.-J. Xiao, S. Wang, G. Xu, X.-Q. Chen, S.-C. Wu, I. Visoly-Fisher, E. A. Katz, Y. Li, J. Lin, W.-S. Li, Y. Li, Sol. RRL 2018, 2, 1800125 .

[46] J. Liu, J. Leng, K. Wu, J. Zhang, S. Jin, J. Am. Chem. Soc. 2017, 139, 1432.

[47] T. Liu, Y. Jiang, M. Qin, J. Liu, L. Sun, F. Qin, L. Hu, S. Xiong, X. Jiang, F. Jiang, P. Peng, S. Jin, X. Lu, Y. Zhou, Nat. Commun. 2019, 10, 878 .

[48] S. G. Motti, T. Crothers, R. Yang, Y. Cao, R. Li, M. B. Johnston, J. Wang, L. M. Herz, Nano Lett. 2019, 19, 3953.

[49] K. A. Bush, N. Rolston, A. Gold-Parker, S. Manzoor, J. Hausele, Z. J. Yu, J. A. Raiford, R. Cheacharoen, Z. C. Holman, M. F. Toney, R. H. Dauskardt, M. D. McGehee, ACS Energy Lett. 2018, 3, 1225.

[50] A. D. Jodlowski, C. Roldán-Carmona, G. Grancini, M. Salado, M. Ralaiarisoa, S. Ahmad, N. Koch, L. Camacho, G. de Miguel, M. K. Nazeeruddin, Nat. Energy 2017, 2, 972.
[51] K. Domanski, B. Roose, T. Matsui, M. Saliba, S.-H. Turren-Cruz, J.-P. Correa-Baena, C. R. Carmona, G. Richardson, J. M. Foster, F. De Angelis, J. M. Ball, A. Petrozza, N. Mine, M. K. Nazeeruddin, W. Tress, M. Grätzel, U. Steiner, A. Hagfeldt, A. Abate, Energy Environ. Sci. 2017, 10, 604.

[52] S. Gharibzadeh, B. Abdollahi Nejand, M. Jakoby, T. Abzieher, D. Hauschild, S. Moghadamzadeh, J. A. Schwenzer, P. Brenner, R. Schmager, A. A. Haghighirad, L. Weinhardt, U. Lemmer, B. S. Richards, I. A. Howard, U. W. Paetzold, Adv. Energy Mater. 2019, 9, 1803699.

[53] T. M. Koh, V. Shanmugam, X. Guo, S. S. Lim, O. Filonik, E. M. Herzig, P. Müller-Buschbaum, V. Swamy, S. T. Chien, S. G. Mhaisalkar, N. Mathews, J. Mater. Chem. A 2018, 6, 2122.

[54] J. Wang, J. Leng, J. Liu, S. He, Y. Wang, K. Wu, S. Jin, J. Phys. Chem. C 2017, 121, 21281. 